\title{
'Novos' sujeitos na gramática infantil do português brasileiro
}

\section{New subjects in the Brazilian Portuguese children's grammar}

\author{
Sandra Quarezemin \\ Universidade Federal de Santa Catarina/CNPq, Florianópolis, Santa Catarina, Brasil
}

\author{
Camila Rezende \\ Universidade Federal de Santa Catarina, Florianópolis, Santa Catarina, Brasil
}

\begin{abstract}
Resumo: Este artigo apresenta os resultados de um estudo em fase inicial sobre o aparecimento de 'novos' sujeitos no português brasileiro infantil, os sujeitos locativos e os possessivos. A gramática do português brasileiro (PB) vem apresentando um número crescente de sentenças com sujeitos considerados atípicos. O objetivo deste estudo é investigar se tais construções já estão presentes na gramática infantil do $\mathrm{PB}$, para tanto, serão apresentados os resultados de duas atividades linguísticas, julgamento de gramaticalidade e tarefa de encenação. Tendo em mente que os falantes do PB optam pelo preenchimento da posição sujeito a deixá-la vazia, mesmo sendo preenchida por constituintes não selecionados diretamente pelo verbo, as hipóteses deste estudo são: (i) a criança reconhece as estruturas com sujeitos locativo e possessivo desde as fases iniciais e (ii) a produção de tais sentenças só ocorre em fases mais avançadas do processo de aquisição.
\end{abstract}

Palavras-chave: Sintaxe; 'Novos’ Sujeitos; Gramática Infantil

\begin{abstract}
This paper shows the results of an initial study on the emergence of 'new' subjects in the children's grammar of Brazilian Portuguese, the locative and possessive subjects. The grammar of Brazilian Portuguese (BP) has been showing an increasing number of sentences with atypical subjects. The goal of this study is to investigate whether such constructions are already present in the children's grammar of PB, therefore, the results of two linguistic tasks, judgment of grammaticality and elicited production, will be presented. The hypotheses of this study take into account the fact that PB speakers choose to fill in the subject position instead of leaving it empty. Even though the position is filled by a constituent that was not directly selected by the verb. This fact leads us to test whether: (i) the child recognizes structures with locative and possessive subjects from the initial stages and (ii) the production of such sentences only occurs in more advanced stages of the acquisition process.
\end{abstract}

Keywords: Syntax; 'New’ Subjects; Children's Grammar

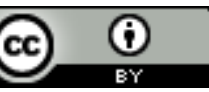




\section{Introdução}

Este artigo apresenta os resultados preliminares de um estudo em fase inicial sobre o aparecimento de 'novos' sujeitos na gramática das crianças do português brasileiro (PB), os sujeitos locativos e os possessivos ${ }^{1}$. A gramática do PB adulto vem apresentando um número crescente de sentenças com sujeitos considerados atípicos. O preenchimento da posição sujeito por sintagmas que não são DPs argumentais (primeiramente apontado em Pontes (1987)) tem levado a associação do PB às línguas tópico proeminente, afastandoo das línguas indo-europeias.

Este trabalho parte do pressuposto de que o ser humano é biologicamente dotado de um dispositivo de linguagem que lhe permite perceber e analisar os dados da fala. De acordo com a perspectiva inata da linguagem, aquilo que é comum às línguas humanas não é passível de aquisição. Todo ser humano vem equipado com um sistema computacional linguístico, que possibilita operações de combinação dos itens lexicais em sintagmas. Neste caso, a criança necessita apenas da exposição à língua alvo para que adquira o léxico e coloque as operações em funcionamento (CHOMSKY, 2005).

Desta forma, a especificidade de uma dada língua é revelada pela aquisição da sintaxe como o resultado de um processo de identificação que ocorre a partir do meio linguístico a que a criança está exposta. As crianças, então, identificam as propriedades dos itens lexicais que guiam as combinações sintáticas. Essa identificação começa a ser feita a partir dos padrões recorrentes detectados pela criança nos dados de fala, segundo a faculdade de linguagem que orienta esse processo.

Tendo em mente que os falantes do PB optam pelo preenchimento da posição sujeito, mesmo sendo preenchida por constituintes não selecionados diretamente pelo verbo, este estudo parte das hipóteses de que (i) a criança reconhece as estruturas com sujeitos locativo e possessivo desde as fases iniciais e (ii) a produção de tais sentenças só ocorre em fases mais avançadas do processo de aquisição. Essa situação nos faz questionar se dentro das possibilidades de novos sujeitos no $\mathrm{PB}$, haveria estruturas que emergiriam antes de outras? Seriam algumas menos complexas do que outras?

\footnotetext{
${ }^{1}$ Os resultados deste estudo foram apresentados no Seminário Internacional de Aquisição da Linguagem, realizado na UFSC. Agradecemos aos participantes pelos comentários e sugestões. Os erros remanescentes são de nossa responsabilidade. Destaca-se que o emprego do termo 'gramática infantil' ou 'gramática da criança' refere-se ao conhecimento linguístico da criança em fase de aquisição.
} 
Este artigo apresenta os resultados de duas atividades linguísticas ${ }^{2}$ que visam a investigar a compreensão e produção das sentenças com sujeitos inovadores no português brasileiro infantil. Antes de entrar no estudo de produção eliciada ${ }^{3}$, será apresentada uma discussão acerca da sintaxe do sujeito no $\mathrm{PB}$ adulto ${ }^{4}$. O artigo foi organizado da seguinte forma: na primeira seção, uma distinção entre sujeito lógico e sujeito gramatical é apresentada; na segunda seção, são enfocados alguns dos sujeitos inovadores presentes na gramática do PB adulto; em seguida, as atividades linguísticas são apresentadas; por fim, uma discussão dos dados é realizada.

\title{
2 Sujeito gramatical versus sujeito lógico
}

O PB é uma língua de núcleo inicial e ordem de palavras básica Sujeito-Verbo-Objeto (SVO). Com a queda parcial do sujeito nulo, a primeira posição passou a ser preenchida com mais frequência. De acordo com Corrêa, Augusto e Lima-Júnior (2017, p. 203):

\begin{abstract}
$\mathrm{Na}$ interface entre a sintaxe e a semântica, atribui-se caracteristicamente ao sujeito lógico o papel temático de agente da ação ou de experienciador do estado ou processo apresentado pelo verbo. Ao objeto lógico, é atribuído o papel de tema ou de paciente (se animado, com verbo de ação).
\end{abstract}

Nas sentenças com voz ativa, como em (1a), o sujeito lógico coincide com o sujeito gramatical, que é aquele que entra em relação de concordância com o verbo. Já nas sentenças com a voz passiva essa coincidência se perde, uma vez que o sujeito gramatical corresponde ao argumento interno do verbo, como em (1b).

(1) a. João comprou o carro.

b. O carro foi comprado pelo João.

\footnotetext{
${ }^{2}$ Usamos o termo 'atividades linguísticas' porque não aplicamos um experimento controlado e com um número elevado de crianças. Os achados mostrados aqui estão mais próximos de um estudo de caso.

${ }^{3}$ Para realizar as atividades linguísticas com as crianças, a primeira autora submeteu o projeto de pesquisa A arquitetura da sentença no Português Brasileiro - um estudo sobre sujeito e tópico à aprovação do Comitê de Ética da UFSC, CAAE: 87443118.7.0000.0121.

${ }^{4}$ Por se tratar de um estudo em fase inicial, a discussão sobre a sintaxe dos 'novos' sujeitos está fundamentada na gramática do PB adulto. As autoras não encontraram até o momento trabalhos de aquisição da linguagem que tratassem do sujeito locativo e possessivo. Foi possível encontrar nos trabalhos de Grolla $(2000,2006)$ uma discussão sobre a aquisição da estrutura tópico-comentário, mas limitada ao tópico objeto. Sobre sentenças absolutas no português brasileiro infantil, ver Rezende (2016). O trabalho de Grolla e Augusto (2016) trata das construções absolutas empregadas pelas crianças para evitar as relativas objeto.
} 
Em (1)b, o argumento interno o carro foi movido para a posição de sujeito gramatical, por meio da operação sintática de deslocamento de constituintes. As sentenças passivas não são a única estratégia possível para o movimento do objeto para a posição de sujeito gramatical. Atualmente, é possível encontrar na gramática do PB adulto sentenças como (2). Negrão e Viotti (2014, p. 317) retiraram este dado de uma campanha publicitária.

(2) A cada minuto quatro coisas vendem.

Esta sentença foge ao padrão regular do PB em que o sujeito de uma sentença com verbo transitivo do tipo vender normalmente é expresso por um constituinte mais animado. O constituinte quatro coisas desencadeia a concordância do verbo vender, é o sujeito gramatical da frase. E quanto ao sujeito lógico? Afinal de contas o verbo vender pressupõe como sujeito alguém que possa executar a atividade de venda, um sintagma [+humano, +animado]. Negrão e Viotti (2014) associam este tipo de sentença a um grau alto de impessoalização, diferentemente das sentenças com alternância que aceitam a inserção do pronome se, como em $A$ porta se abriu, ou a formação passiva, como em $A$ porta foi aberta pelo Pedro.

Segundo Corrêa, Augusto e Lima-Júnior (2017), em um estudo sobre as sentenças passivas, as propriedades formais, capturadas pelas crianças nos dados de fala, sinalizam que o argumento interno de um verbo transitivo pode se realizar como sujeito gramatical na língua alvo. Observamos que as línguas apresentam dados robustos para indicar que não há uma sobreposição entre sujeito lógico e sujeito sintático. As crianças precisam apreender que tipos de estruturas permitem essa não sobreposição na língua alvo. A questão central deste estudo é investigar se as crianças em fase de aquisição do PB compreendem as sentenças com sujeitos locativos e possessivos. Também faz parte do escopo deste trabalho verificar se as crianças produzem sentenças que não apresentam coincidência entre sujeito lógico e sujeito gramatical. Este tipo de sujeito está sendo denominado neste estudo de inovador. 


\section{3 'Novos' sujeitos no PB adulto}

Pontes (1987) verifica que o PB, diferentemente do português europeu (PE), aceita construções em que um constituinte não argumental desencadeia concordância com o verbo, como em (3).

(3) Essas casas batem sol.

A partir da observação de que a concordância verbal pode afetar tópicos, a autora propõe que o $\mathrm{PB}$ tenha evoluído no sentido de se tornar uma língua de proeminência de tópico. Avelar e Galves (2011, p. 69) também afirmam que o PB se diferencia do PE pelo fato de apresentar sentenças como (4), com a concordância realizada com uma espécie de "tópico-sujeito",

(4) Os carros furaram o pneu.

$\left(\mathrm{PB}^{\mathrm{ok}} ; \mathrm{PE}^{*}\right)$

A ocorrência desses dados nos permite formular a hipótese de que a posição sujeito no PB é flexível e aceita constituintes de natureza diversas, o que nos leva a investigar se estes dados já estão presentes na gramática do PB infantil. As crianças compreendem e produzem sentenças com locativo e possessivo em posição sujeito? Se as crianças rapidamente capturam as propriedades da língua a que são expostas, tendo em seu ambiente linguístico sentenças como (4), o esperado é que elas não estranhem dados como esses.

Na grande maioria das línguas indo-europeias, a concordância se dá entre a flexão verbal e o sujeito lógico da frase ou um sintagma argumental. Raramente a concordância ocorre com termos que não integram a grade temática do verbo. Dados como o que foi apresentado em (4) mostram que o PB apresenta uma sintaxe diferenciada, pelo menos das línguas indo-europeias.

\footnotetext{
${ }^{5}$ Encontramos na literatura diferentes análises para este tipo de sentença: alguns autores propõem uma estrutura de tópico (cf. NEGRÃO, 1999; KATO, 2006); outros afirmam que a posição Spec,TP pode ser projetada para receber sintagmas não-argumentais (cf. GALVES, 1999; LUNGUINHO, 2006; 2017); há autores que defendem que Spec,TP é uma posição A-barra (cf. AVELAR; CYRINO, 2008; AVELAR, 2009); Quarezemin e Cardinaletti (2017), seguindo a abordagem cartográfica, propõem que os locativos e possessivos se movem para Spec,SubjP onde checam o traço "sujeito da predicação".
} 
Nas sentenças com sujeito possessivo, o sintagma que concorda com a flexão verbal equivale semanticamente a um termo adnominal preposicionado interpretado como possuidor, como verificamos em (5), exemplo extraído de Avelar e Galves (2013, p. 113).

(5) Os carros acabaram a gasolina no meio da viagem.

Também encontramos nos dados do PB um sistema de concordância locativa, conforme atestado por Avelar e Galves (2013, p.107-108). O verbo concorda com o sintagma locativo que não equivale ao sujeito lógico (ou semântico), como nos exemplos (6) e (7).

(6) As ruas do centro não tão passando ônibus.

Ao contrário da tendência observada entre as línguas indo-europeias, todos os casos apresentados são de construções em que um sintagma analisado tradicionalmente como adjunto adverbial (ou complemento locativo) figura em posição pré-verbal e concorda com o verbo. Ainda observamos que o sintagma preposicionado pode aparecer em posição pré-verbal sem a marcação da pausa:

(7) Naquela loja vende livros.

Diante do cenário apresentado, com sentenças nas quais o sujeito gramatical não corresponde ao sujeito lógico, chamado aqui de sujeito inovador, este estudo investiga se as crianças do PB reconhecem e aceitam estas estruturas. Também atentamos para a produção destas sentenças pelas crianças. Tais sentenças já fazem parte da gramática infantil do PB? Há uma faixa etária específica para o aparecimento destas construções? Dentro das possibilidades de novos sujeitos no $\mathrm{PB}$, haveria estruturas que emergiriam antes de outras? Seriam algumas menos complexas do que outras?

Recorremos a duas atividades linguísticas para testar se este cenário linguístico reflete na gramática da criança, que reconhece estruturas com sujeito locativo e possessivo desde muito cedo (hipótese I) e se a criança compreende e produz estas 
sentenças, uma vez que as estruturas com alçamento de locativos e possessivos ${ }^{6}$ fazem parte do seu input (hipótese II). Antes de passarmos aos resultados, faremos uma breve incursão sobre alguns aspectos sintáticos na gramática do PB infantil.

\section{Atividades linguísticas com crianças do português brasileiro}

Para investigar se os sujeitos inovadores já estão aparecendo na gramática do PB infantil, analisamos o comportamento linguístico de um pequeno grupo de crianças ${ }^{7}$ de Florianópolis. Os dados desta pesquisa foram obtidos através de visitas semanais durante o período de dois meses ao Núcleo de Desenvolvimento Infantil (NDI) da Universidade Federal de Santa Catarina (UFSC).

Em busca de resultados confiáveis e de diferentes maneiras de avaliar o conhecimento linguístico das crianças, optamos por duas atividades linguísticas: o julgamento de gramaticalidade e o método da elicitação. Antes de realizar a atividade de julgamento de gramaticalidade, foi feita uma coleta de dados de produção espontânea, com o intuito de observar se a criança produziria sentenças com os 'novos' sujeitos sem um método de elicitação. A coleta dos dados espontâneos ocorreu, em grande parte, no ambiente de sala de aula. Buscamos acompanhar as crianças sem atrapalhá-las em sua rotina, logo, ocorreram algumas gravações no parque também. As gravações foram feitas a partir do aplicativo de gravador de áudio do celular Iphone.

As crianças participantes desta pesquisa pertencem a três diferentes grupos do NDI, que têm como critério a faixa etária para a sua formação. Acompanhamos quatro crianças do grupo 4, com faixa etária de três a quatro anos, três crianças do grupo 5, com faixa etária de quatro a cinco anos e duas crianças do grupo 6, com faixa etária de cinco a seis anos, totalizando nove crianças.

A gravação de dados espontâneos ocorreu no primeiro momento da coleta e teve duração média de um mês e meio. Durante este período acompanhamos cada grupo individualmente uma vez por semana. As sessões ocorriam no início da tarde no horário

\footnotetext{
${ }^{6}$ Testamos sentenças com possessivo e locativo em posição pré-verbal, porque ainda que envolvam o alçamento de constituintes distintos, elas têm em comum o fato de sintagmas não argumentais aparecerem na posição considerada típica de sujeito.

${ }^{7}$ As atividades foram realizadas com um grupo bem reduzido de crianças, porque se trata de um estudo piloto para que, futuramente, possamos elaborar um experimento eficaz que será aplicado a um grupo maior.
} 
em que as crianças chegavam na escola e finalizavam no momento do lanche. As sessões tinham duração média de duas horas em cada grupo.

As professoras auxiliaram a pesquisadora nos primeiros contatos com a turma e com as crianças participantes com a finalidade de quebrar a barreira de timidez da criança. Normalmente, as professoras inseriam a pesquisadora em alguma atividade ou brincadeira em que a criança estava e, assim, era possível estimular a fala espontânea das crianças até o fim da sessão. As atividades consistiam em desenhos e pinturas ou brincadeiras com bonecos e carrinhos, atividades tranquilas para as crianças dialogarem com os adultos e com os colegas de classe.

Não apareceu nenhuma ocorrência de sujeito locativo ou de sujeito possessivo nos dados de produção espontânea das crianças dos grupos 4 e 5. No grupo 6, uma das crianças respondeu à pergunta da pesquisadora com uma construção com sujeito possessivo, como em (8).

(8) Experimentadora: $\mathrm{O}$ que aconteceu aqui?

Criança: O carro rachou a janela. $(5 ; 6)$

Sobre uma mesa na sala de aula da criança, havia um desenho de um carro com o vidro da janela quebrado, ao ser questionada pela entrevistadora sobre o que ocorrera ali, a criança responde com a sentença em (8). Em todo o nosso corpus de dados espontâneos, este foi o único dado com a ocorrência de um sintagma possessivo alçado para a posição de sujeito pré-verbal. Esse resultado sinaliza uma produção tardia do que consideramos ser os 'novos' sujeitos. Além disso, parece haver um descompasso entre a compreensão (precoce) e a produção (tardia) desse tipo de sentença.

\subsection{Atividade linguística 1: produção eliciada e julgamento de gramaticalidade}

Após um mês e meio de coleta de dados espontâneos e maior familiaridade entre a pesquisadora e as crianças, iniciou-se a coleta de dados eliciados, com a finalidade de averiguar se as crianças participantes produzem sujeitos inovadores. Segundo Grolla (2009), a produção eliciada possibilita ao pesquisador revelar a gramática das crianças, uma vez que a finalidade desta atividade é fazer com que elas produzam sentenças 
particulares, que não são facilmente encontradas em um contexto de produção espontânea.

\subsubsection{Método}

Participantes: Esta atividade contou com a participação de quatro crianças do grupo 4 e com três crianças do grupo 5 . As crianças do grupo 4 compreendiam a faixa etária entre os $3 ; 8$ e $4 ; 1$. Já as crianças do grupo 5 compreendiam a faixa etária entre os $4 ; 9$ e $5 ; 1^{8}$.

Material: Para a realização da atividade foram usadas figuras com desenhos ilustrados, uma fruta e um pedaço de pneu feitos de papel, além de um fantoche. ${ }^{9}$

Procedimento: A coleta dos dados de testes eliciados ocorreu com cada criança individualmente junto da entrevistadora e um auxiliar, em uma sala privada de barulho. Caso as crianças mostrassem desinteresse, cansaço ou qualquer interferência que pudesse comprometer os resultados, a sessão era interrompida. $\mathrm{O}$ procedimento teve a duração média de doze minutos. Em um primeiro momento, a executora da atividade apresentava para a criança a Mimosa, um fantoche em forma de vaca, contava que a Mimosa tinha vindo do planeta das vacas e que queria aprender mais sobre o planeta dos humanos. Ainda contava que a Mimosa tinha dificuldade com algumas coisas do nosso planeta e convidava a criança para apresentar à Mimosa algumas coisas do mundo dos humanos. Nesta etapa do teste, a executora mostrava uma figura de cada vez e perguntava para a criança o que se fazia no ambiente mostrado ou o que tinha acontecido ao objeto mostrado, a tarefa da criança era responder para o fantoche o que lhe foi perguntado. Neste piloto, as estruturas-alvo eram sentenças com sujeito possessivo e sentenças com sujeito locativo.

\footnotetext{
${ }^{8}$ Durante a realização das atividades, a professora do grupo 6 estava afastada por motivo de saúde e a coordenadora pedagógica do NDI nos pediu para aguardar a volta dela para que realizássemos a coleta com as crianças desse grupo. Infelizmente, não foi possível realizar a coleta de dados desse grupo no tempo previsto, ficando, assim, fora deste trabalho.

${ }_{9}^{9}$ Para as duas atividades, escolhemos objetos e imagens que fazem parte do universo infantil, a intenção foi tornar a atividade mais natural para a criança. Os objetos e imagens foram confeccionados de acordo com o contexto em que a sentença-alvo estava inserida.
} 
(9) A flor quebrou a pétala.

(10) Na biblioteca lê livro.

Se o esperado era que a criança produzisse uma estrutura nos moldes de (9), por exemplo, era mostrado a ela uma figura com a pétala quebrada. Se o esperado era que a criança produzisse uma estrutura nos moldes de (10), era mostrado a ela uma figura em que uma criança estava lendo um livro em uma biblioteca. Para as sentenças com deslocamento do possessivo eram usadas perguntas do tipo "o que aconteceu aqui?" e para as sentenças com sujeito locativo eram empregadas perguntas do tipo "o que se faz aqui?". ${ }^{10}$ Cada gravura era mostrada individualmente e intercalada com figuras distratoras.

No segundo momento do teste, a tarefa de julgamento de gramaticalidade passou a ser realizada. Após a criança contar para o fantoche o que ocorria em todas as figuras apresentadas, a entrevistadora a convidava para checar se o fantoche realmente entendeu o que lhe foi dito. $\mathrm{O}$ fantoche deveria explicar para a criança o que tinha acontecido em cada figura. Caso relatasse de maneira que a criança julgava gramatical, ela deveria dar a Mimosa uma fruta; se o fantoche dissesse algo que não fazia sentido para a criança, ela deveria dar a ele um pedaço de pneu.

Se a criança desse ao fantoche um pedaço de pneu, sinalizaria que ela não reconheceu a sentença dita como uma estrutura possível na sua língua-alvo. Logo, se a criança lhe desse uma fruta, sinalizaria que compreendeu tal estrutura. Durante este momento da atividade, também usamos as gravuras distratoras.

Resultados e discussão: Dos dados obtidos na realização da atividade apenas uma criança produziu uma construção com locativo em posição pré-verbal, reproduzida em (11).

(11) Na biblioteca lê livros e não pode fazer barulho. $(5 ; 1)$

\footnotetext{
${ }^{10}$ Temos consciência de que sentenças com sujeito possessivo e locativo (sem pausa) são estruturas mais difíceis de eliciar. Quando formos elaborar o experimento com as crianças, recorreremos a um grupo controle de adultos para que se possa, pelo menos, verificar se o teste realmente funciona.
} 
Convém mencionar que a sentença acima foi dita logo após o fantoche ver a gravura de uma criança lendo um livro na biblioteca e dizer "na biblioteca lê livro". A produção da criança pode ter sido proveniente de imitação, de qualquer forma, é notável que a ocorrência se deu com a criança mais velha participante da atividade linguística. Esse momento lembra situações de priming linguístico, que tem sido um tipo de teste bastante utilizado para a eliciação de passivas, também uma estrutura de pouca frequência na fala de crianças (cf. MESSENGER et al. (2012).

Além da ausência de produção, a criança mais nova participante do experimento $(3 ; 8)$ recusou todas as sentenças-alvo. Em todas as situações ela deu ao fantoche um pedaço de pneu, o que parece indicar uma aquisição tardia deste fenômeno. É válido frisar que essa criança se mostrou apta à participação no teste. As demais crianças do experimento não produziram nenhuma sentença com sujeito possessivo e locativo, entretanto, compreenderem todas as estruturas-alvo. Ainda observamos que a criança de $(3 ; 9)$ e a de $(3 ; 10)$, idades muito próximas da criança que recusou as sentenças-alvo, não tiveram problemas de compreensão e aceitabilidade. $\mathrm{O}$ experimento piloto revelou uma dissociação entre compreensão e produção das sentenças-alvo durante o processo de aquisição da linguagem.

\subsection{Atividade linguística 2: tarefa de encenação}

Ao finalizarmos o teste de produção eliciada e o teste de julgamento de gramaticalidade, demos uma pausa de 5 meses de coleta e voltamos com uma única sessão de coleta de dados com o experimento de tarefa de encenação.

\subsubsection{Método}

Participantes: Esta atividade também contou com a participação de quatro crianças do grupo 4 e com três crianças do grupo 5. Neste momento, as crianças do grupo 4 compreendiam a faixa etária entre os 4,1 e 4;3. Já as crianças do grupo 5 compreendiam a faixa etária entre os 5,2 e 5;6. 
Material: Para a realização da atividade fizemos objetos de material EVA com partes removíveis, contamos com o auxílio de animais de pelúcia, entre outros objetos, como mostrado nas figuras abaixo. ${ }^{11}$

Figura 1 - Exemplo de objetos em EVA utilizados na atividade
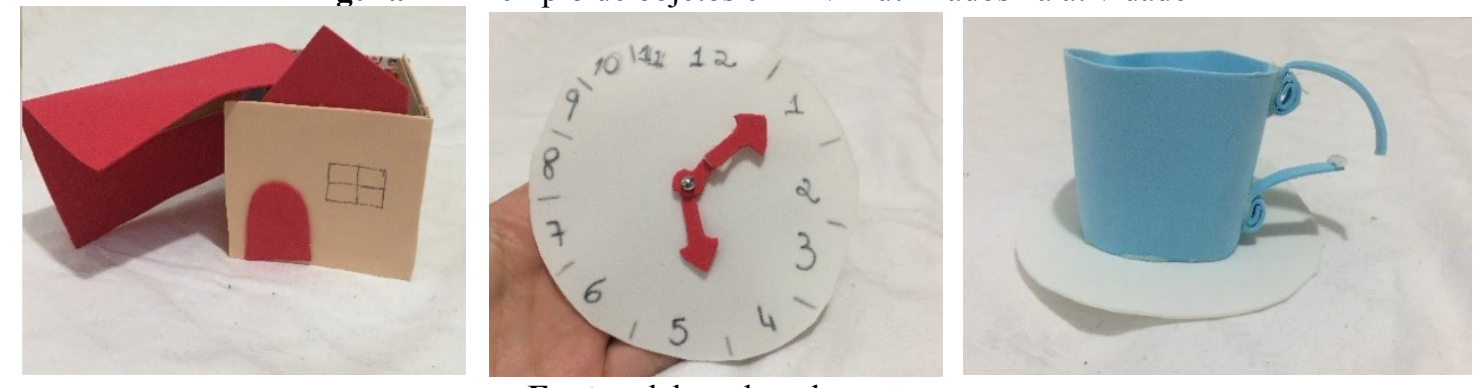

Fonte: elaborado pelas autoras.

Procedimento: Assim como na atividade anterior, o ambiente utilizado para a realização da coleta era desprovido de barulho e outras distrações que pudessem interferir na performance da criança durante o teste. O procedimento também teve a duração média de doze minutos.

A executora apresentava para a criança o personagem principal chamado Roberto, um macaco de pelúcia, e explicava que a dinâmica da brincadeira consistia em ela encenar com o auxílio dos bonecos e objetos alguns acontecimentos da história que a experimentadora iria narrar. A história foi iniciada com três tarefas-teste de encenação para averiguar se a criança havia entendido a atividade e estava apta para participar do experimento. Para as tarefas-teste usamos atos simples e de fácil compreensão, como em (12).

(12) Executora diz: Um dia Roberto estava caminhando distraído e de repente sentiu uma coceira muito forte e coçou o pé.

A criança, então, encena o boneco coçando o pé.

A história se passa em torno do encontro de dois amigos, Roberto e Gustavo, que decidem ir até a casa de Gustavo. Durante o trajeto, algumas coisas vão acontecendo. A executora, então, sinaliza com uma pausa na narração o momento em que a criança deve

\footnotetext{
${ }^{11}$ Os objetos foram manipulados como uma forma de gatilho para a produção das sentenças-alvo. Por exemplo, ao ver que o telhado da casa não é fixo, a criança seria levada a produzir uma sentença para ilustrar essa situação.
} 
fazer a encenação, conforme a história narrada. As sentenças-alvo desta atividade limitaram-se apenas às sentenças com sujeito possessivo, como em (13).

(13)a. O tênis desamarrou o cadarço.

b. A xícara rachou a alça.

Os objetos disponíveis para as crianças manusearem durante a encenação eram adaptados para a realização da ação narrada. Logo, a casa possuía um telhado removível, o tênis possuía um laço de fácil desatamento e os demais objetos possuíam fita duplaface, assim, era possível, por exemplo, retirar uma perna da mesa e colá-la de volta ${ }^{12}$. Neste experimento, também havia sentenças distratoras entre as sentenças alvos para despistar as crianças e averiguar se elas estavam participando do teste de maneira eficaz. A narração ocorria de forma natural como qualquer história infantil. Os objetos para a encenação vão aparecendo no cenário conforme o desenrolar da história, para que as crianças não se distraiam tendo muitos objetos para manusear.

Resultados e discussão: No geral, os resultados da tarefa de encenação mostraram que as oito crianças participantes da atividade compreenderam as sentenças com o movimento do possessivo para a posição de sujeito. Nenhuma criança demonstrou dificuldade de compreensão, todas conseguiram encenar as sentenças-alvo proferidas. O mesmo não pode ser dito em relação à produção desse tipo de sentença. Quando a executora questionava a criança sobre o que havia acontecido, ela respondia com uma sentença padrão, sem alçamento de sintagma possessivo.

Apesar de a criança produzir a sentença-alvo, ao ser questionada novamente sobre o que aconteceu na história, ela prefere o uso da estrutura canônica em sua resposta, sem o alçamento do possessivo, ao invés da estrutura tópico-sujeito (PONTES, 1987). Os resultados desta atividade indicam que, ainda que as crianças não tenham apresentado dificuldade na compreensão da sentença-alvo, essa estrutura não pode ser considerada default no português brasileiro, uma vez que a produção do fenômeno é muito baixa. Em um caso, parece que a criança se esforçou para a produção da sentença com o alçamento

\footnotetext{
${ }^{12}$ Para a elaboração do experimento de fato, vamos fazer com que outras partes do objeto também possam ser removíveis. Desse modo, a criança não ficará com algo diante de si que tem apenas uma opção de manuseio.
}

Revista da Anpoll, Florianópolis, v. 52, n. 1, p. 188-204, jan-maio, 2021 | 200 
do possessivo, entretanto, ela faz uma pausa e retoma a estrutura canônica. A criança topicalizou o possessivo a flor (a pétala da flor) e retomou com o constituinte a pétala, ao invés de usar um pronome resumptivo.

\section{Discussão geral dos resultados}

As crianças participantes das atividades não mostraram dificuldade em compreender as sentenças-alvo, seguindo corretamente o comando que tinha sido passado pela executora, tanto na tarefa de encenação quanto na tarefa de julgamento de gramaticalidade. As hipóteses desse estudo foram confirmadas: a criança reconhece desde muito cedo as estruturas com 'novos' sujeitos, mas raramente produzem-nas, optando sempre pela sentença padrão com sujeito lógico em posição pré-verbal. A dissociação entre a compreensão e a produção pode estar relacionada a fatores de performance da criança, não a um conhecimento linguístico deficiente. Corrêa, Augusto e Lima-Júnior apontam que sentenças com alternância sintática, do tipo $O$ copo quebrou, não apresentam problemas de compreensão para as crianças.

O que parece estar em jogo na produção de sentenças com 'novos' sujeitos é o caráter inovador desse tipo de construção, já que na posição default de sujeito aparece um sintagma que não tem propriedade agentiva. Parece que o alçamento desse tipo de constituinte está vinculado ao fato de os falantes do PB preencherem cada vez mais a posição do sujeito na fala. Segundo Grolla (2000, p. 58), “a presença de um determinado fenômeno linguístico no input não implica necessariamente em sua rápida aquisição por parte da criança". A autora verificou que as estruturas de topicalização e comp duplamente preenchido ${ }^{13}$, ainda que abundantes no input da criança, surgiram apenas aos 2;9 de idade.

A assimetria verificada entre a compreensão e a produção de sentenças com sujeitos inovadores não é surpreendente. Grolla e Augusto (2014) observaram que as crianças aceitam sentenças com pronomes resumptivos com mais frequência do que as produzem, o que indica que o comportamento linguístico da criança não é idêntico ao do adulto.

\footnotetext{
${ }^{13}$ Nestas construções, as posições do especificador de CP e do núcleo C são lexicalmente preenchidos: (i) O que que a menina fez?
} 
Parece que a produção da criança é, de alguma forma, afetada por fatores de ordem semântica. Corrêa, Augusto e Lima-Júnior (2017, p. 208) observaram, no estudo sobre a aquisição das passivas, que "as crianças também se mostram afetadas pela plausibilidade do evento descrito". Segundo os autores, a taxa de acertos tende a ser maior quando a sentença retrata um evento plausível. No caso das sentenças com possessivo e locativo em posição de sujeito, como em (13) e (14), respectivamente, verificamos que os eventos descritos não são plausíveis, ou, pelo menos, parcialmente plausíveis, afinal de contas uma pétala não 'quebra' nada, assim como uma biblioteca não tem condição de 'ler' livros.

\section{Considerações finais}

Este trabalho apresentou os primeiros resultados de um estudo em fase inicial sobre o aparecimento de 'novos' sujeitos no português brasileiro infantil, os sujeitos locativos e os possessivos. Com a finalidade de investigar se tais construções já estão presentes na gramática infantil do $\mathrm{PB}$, foram apresentados os resultados de duas atividades linguísticas, o julgamento de gramaticalidade e a tarefa de encenação. No geral, os resultados dessas atividades apontam que, ainda que as crianças não tenham dificuldade na compreensão da sentença-alvo, essa estrutura não pode ser considerada default no português brasileiro, uma vez que a produção de tais sentenças é baixa. Nas situações em que a executora incitava as crianças na busca por dados eliciados, elas responderam com uma sentença padrão, sem 'novos' sujeitos.

As hipóteses desse estudo foram confirmadas: a criança reconhece desde muito cedo as estruturas com 'novos' sujeitos, mas raramente produzem-nas, optando sempre pela sentença padrão com sujeito lógico em posição pré-verbal. Ainda que tais sentenças ocorram na gramática do PB adulto, as crianças raramente produzem-nas, optando sempre pela sentença padrão.

O que parece estar em jogo na produção de sentenças com 'novos' sujeitos pelas crianças é a complexidade envolvida nesse tipo de construção. Esta estratégia inovadora deve ter um custo para os sistemas de interface que interfere na produção de sentenças com sujeito locativo e possessivo. A criança parece ter dificuldade de selecionar um sujeito que não seja lógico, comprometendo a produção de tais sentenças. 


\section{Agradecimentos}

S.Q. é bolsista de Produtividade em Pesquisa (PQ-2) do Conselho Nacional de Desenvolvimento Científico e Tecnológico (CNPq).

\section{Contribuição}

Sandra Quarezemin: Conceptualização, Curadoria de Dados, Análise Formal, Investigação, Metodologia, Administração do Projeto, Recursos, Supervisão, Validação, Visualização, Escrita - rascunho original, Escrita - análise e edição; Camila Rezende:

Curadoria de Dados, Investigação, Metodologia, Validação, Visualização, Escrita rascunho original.

\section{Referências}

AVELAR, J.; GALVES, C. Tópico e concordância em português brasileiro e português europeu. In: Textos selecionados - XXVI Encontro da Associação Portuguesa de Linguística. Lisboa: APL, 2011. p. 69-45

AVELAR, J.; GALVES, C. Concordância locativa no português brasileiro: questões para a hipótese do contato. In: MOURA, M. D.; SIBALDO, M. (orgs.), Para a História do Português Brasileiro. $1^{a}$ ed. Maceió: Edufal, p. 103-132, 2013.

CHOMSKY, N. Three factors in language design. Linguistic Inquiry, v. 36, n.1, p. 1$22,2005$.

CORRÊA, L.; AUGUSTO, M.; LIMA-JÚNIOR, J. P. In: FREITAS, M. J; SANTOS, A. L. (orgs.), Aquisição de língua materna e não materna: Questões gerais e dados do português (Textbooks in Language Sciences 3). Berlin: Language Science Press, p. 201-224, 2017.

GROLLA, E. A aquisição da periferia esquerda da sentença em Português Brasileiro. Dissertação de Mestrado, Unicamp, 2000.

GROLLA, E. A Aquisição da Linguagem. Material didático desenvolvido para o Curso Letras - LIBRAS da Universidade Federal de Santa Catarina, 2006.

GROLLA, E. Metodologias experimentais em aquisição da linguagem. Revista Estudos da Lingua(gem), v. 7, p. 9-42, 2009.

GROLLA, E.; AUGUSTO, M. Absolutive Constructions in Brazilian Portuguese and Relativized Minimality Effects in Children's Productions. In: Proceedings of Generative Approaches to Language Acquisition (2015), 2016. 
GROLLA, E.; AUGUSTO, M. Pronomes resumptivos em português brasileiro infantil: dados de produção e compreensão. Cadernos de Letras da UFF - Dossiê: Anáfora e correferência: temas, teorias e métodos, n. 49, p. 133-154, 2014.

MESSENGER, K. et al. Is young children's passive syntax semantically constrained? Evidence from syntactic priming. Journal of Memory and Language, v. 66, n. 4, p. 568-587, 2012.

NEGRÃO, E. Português brasileiro: uma língua voltada para o discurso. Tese de Livre Docência. Universidade de São Paulo, 1999.

NEGRÃO, E.; VIOTTI, E. Contato entre quimbundo e português clássico: impactos na gramática de impessoalização do português brasileiro e angolano. Linguística, v. 30, n. 2, p. 289-330, 2014.

PONTES, E. O tópico no português brasileiro. Campinas, 1987.

REZENDE, C. Sentenças absolutas no português brasileiro infantil: um estudo experimental. Dissertação de Mestrado. USP, 2016.

Recebido em: 20 de outubro de 2020

Aceito em: 14 de abril de 2021

Publicado em maio de 2021

Sandra Quarezemin

E-mail: sandra@cce.ufsc.br

ORCID: https://orcid.org/0000-0002-8570-5389

Camila Rezende

E-mail: sz.camilacaroline@hotmail.com

ORCID: https://orcid.org/0000-0001-6688-7933 